\title{
Is total-subtotal colectomy and primary anastomosis a good treatment alternative in malignant obstructive lesions of the left colon?
}

\author{
Sol kolonun tıkayıcı malign lezyonlarında total-subtotal kolektomi \\ ve primer anostomoz iyi bir tedavi alternatifi midir?
}

\author{
Kemal ARSLAN, Mehmet Ali ERYILMAZ, Ahmet OKUŞ, \\ Osman DOĞRU, Ömer KARAHAN, Hande KÖKSAL
}

\section{BACKGROUND}

This study was designed in order to compare the effectiveness of subtotal-total colectomy with other surgical methods in the treatment of malignant obstructive lesions of the left colon.

\section{METHODS}

Patients admitting with symptoms of colonic obstruction and treated by emergency surgery in Konya Education and Research Hospital between 2004 and 2007 were enrolled. Patients were divided into three groups according to the surgical procedures (Group I: Hartmann procedure; Group II: resection + diverting ileostomy; Group III: total-subtotal colectomy). Related patient data were evaluated retrospectively.

\section{RESULTS}

The mean age of 62 patients was 64 (38-89) years. There were no significant differences between the groups with respect to gender, age, American Society of Anesthesiology scores, and tumor stages. There were no significant differences between the study groups in terms of operative duration, postoperative mortality, and five-year survival; however, the length of hospital stay and hospitalization costs were lower in Group III compared to the other groups.

\section{CONCLUSION}

We suggest that subtotal-total colectomy performed by experienced surgeons may be a good alternative to the other procedures.

Key Words: Treatment of obstructive lesions of the left colon; total or subtotal colectomy; Hartmann procedure; resection; diverting ileostomy.

\section{$\boldsymbol{A M A C}$}

Bu çalışmada, sol kolonun tıkayıcı malign lezyonlarında total-subtotal kolektomi anostomoz ile diğer cerrahi tedavi yöntemleri karşılaştırıldı.

\section{GEREÇ VE YÖNTEM}

Çalışmaya Konya Eğitim ve Araştırma Hastanesine 20042007 yılları arasında transvers kolon distalinde tıkanıklık bulguları ile başvuran ve cerrahi tedavi uygulanan hastalar dahil edildi. Hastalar cerrahi prosedüre göre üç gruba ayrıld1. Bunlar: Grup I: Hartmann prosedürü; Grup II: Rezeksiyon, anostomoz ve saptırıcı ileostomi; Grup III: Total veya subtotal kolektomi ve primer anastomoz. Hastaların dosyaları geriye dönük olarak incelendi.

\section{BULGULAR}

Altmış iki hastanın yaş ortalaması 64 (dağılım, 38-89 yaş) idi. Birinci grupta 15, ikinci grupta 21, üçüncü grupta 26 hasta vard1. Gruplar arasında yaş ortalamaları, cinsiyet, ASA skoru ve tümör evresi bakımından anlamlı fark yoktu. Çalışma grupları arasında ameliyat süresi ve ameliyat sonrası morbidite, mortalite ve beş yıllık sağkalım açısından anlamlı fark yoktu, ancak hastanede kalma süresi ve tedavi maliyetleri açısından Grup I ve Grup II'ye göre Grup III'de anlamlı olarak düşüktü.

\section{SONUÇ}

Deneyimli cerrahlar tarafindan yapılan total-subtotal kolektomi ve primer anostomozun diğer bir veya iki aşmalı cerrahi prosedürlere göre daha iyi bir alternatiftir.

Anahtar Sözcükler: Sol kolon tıkayıcı tümörlerinin tedavisi, total veya subtotal kolektomi; Hartmann prosedürü; rezeksiyon; sapt1ric1 ileostomi. 
Being the second most common cancer in men and third most common in women, colorectal cancer reaches a peak incidence in the sixth and seventh decades. More than half of these cancers are localized on the left side, which is also the most frequent anatomical localization of colon cancers in general. ${ }^{[1]}$ Right-sided tumors constitute about a quarter of all colon cancers, while synchronous disease may be observed in $5 \%$ of the patients. Localization in the splenic flexure is observed in $4 \%$ of the patients, but this rarest localization is associated with obstruction in half of the cases. ${ }^{[2]}$ Admission with acute obstruction in patients with colon cancers has been reported at rates up to $29 \%$ in different series. ${ }^{[3,4]}$ The most frequent etiological factor in emergent colonic surgeries is malignancies, constituting approximately $60 \%$ of all mechanical obstructions. ${ }^{[5]}$ Emergent surgery in colorectal cancers has been reported to be associated with high mortality and morbidity rates. ${ }^{[6,7]}$

Several surgical procedures have been described for the treatment of obstructive lesions of the left colon; however, there is no consensus on a particular method to be used for the surgical management of acute obstructions due to malignancies. ${ }^{[8,9]}$ The classical three-step surgical approach including initial transverse loop colostomy followed by left colectomy performed after improvement in the patient's general status and closure by colostomy after two or three weeks has started to be replaced with the more aggressive single-step emergent surgery as subtotal colectomy and primary anastomosis. ${ }^{[10,11]}$ Other surgical alternatives include Hartmann resection, intraoperative colonic lavage and primary anastomosis following resection $^{[12]}$ and Mikulicz resection followed by closure via colostomy. ${ }^{[13]}$ The use of rectosigmoid stent as an alternative to initial surgical decompression is currently at an experimental stage. ${ }^{[14]}$ It has been reported in several studies that single-step procedures are more advantageous compared with multi-step procedures in the surgical management of obstructive malignancies of the left colon in terms of short- and long-term survival. $^{[10,11,15-17]}$

This study was designed in order to compare the effectiveness of emergent subtotal-total colectomy and primary anastomosis with other surgical methods in the treatment of malignant obstructive lesions of the left colon.

\section{MATERIALS AND METHODS}

Records of patients admitting with symptoms of colonic obstruction and treated by emergent surgery in the General Surgery Clinic of Konya Training and Research Hospital between January 2004 and March 2007 were evaluated retrospectively. Patients with tumors localized in the distal transverse colon and be- yond were considered as left colonic obstructive tumors.

Demographic characteristics, comorbidities, colonic obstruction level, surgical procedures, operative duration, length of hospital stay, postoperative morbidity and mortality, and five-year survival rates were evaluated. Hospitalization costs were calculated based on prices set by the Social Security Institution. Definitive pathological stages of the patients according to tumor-node-metastasis (TNM) staging system were determined based on pathology reports. Related patient data were retrieved from patient files and hospital computer records. Patients with insufficient information in their files, those undergoing colostomy without resection and those with rectal obstruction were excluded.

Patients were allocated into three groups according to the surgical procedures (Group I: Hartmann procedure; Group II: resection, anastomosis + diverting ileostomy; Group III: total or subtotal colectomy and primary anastomosis). The three groups were compared in terms of postoperative mortality, morbidity, operative duration, length of hospital stay, and treatment costs.

\section{Statistical Analysis}

Statistical analyses were performed using the Statistical Package for the Social Sciences version 13.0 (SPSS Inc., Chicago, IL, USA). Descriptive statistics were performed and the results were presented as number, mean, median, and range. Categorical variables were compared using chi-square test, and numeric variables were compared between the groups using Mann-Whitney U test. A p value of $<0.05$ was considered statistically significant.

\section{RESULTS}

Records of 76 patients treated by emergent surgical resection due to malignant colonic obstruction were examined. In 62 patients, the tumor was localized in the distal transverse colon and beyond. The number of patients, gender distribution and median age according to the three surgical procedure groups are presented in Table 1. The mean age of the patients was 64 years (range 38 to 89 years). There were no significant differences between the groups with respect to gender and age.

The distribution of patients according to comorbidities, American Society of Anesthesiology (ASA) scores, and tumor stages in the study groups are presented in Table 2. There were no significant differences between the groups with respect to comorbidities, ASA scores, and tumor stages.

The distribution of patients with respect to postoperative complications according to study groups is 
Table 1. The number of patients, gender distribution and median age according to the three surgical procedure groups

\begin{tabular}{lcccc}
\hline & Group I & Group II & Group III & $p$ \\
\hline Patients & 15 & 21 & 26 & \\
Male/Female & $10 / 5$ & $13 / 8$ & $16 / 10$ & 0.275 \\
Median age (Years) & $64(40-89)$ & $66(38-87)$ & $62(45-85)$ & 0.192 \\
\hline
\end{tabular}

$\mathrm{p}>0.05$, not significant; Data are given in numbers (ranges).

Table 2. The distribution of patients according to comorbidities, American Society of Anesthesiology scores, and tumor stages

\begin{tabular}{lcccc}
\hline & $\begin{array}{c}\text { Group I } \\
(\mathrm{n}=15)\end{array}$ & $\begin{array}{c}\text { Group II } \\
(\mathrm{n}=21)\end{array}$ & $\begin{array}{c}\text { Group III } \\
(\mathrm{n}=26)\end{array}$ & $p$ \\
\hline Heart disease & 11 & 7 & 12 & \\
Diabetes mellitus & 3 & 6 & 7 & \\
Pulmonary disease & 6 & 12 & 11 & \\
Renal failure & 2 & - & 1 & 0.872 \\
Total & 22 & 24 & 31 & \\
ASA Scores & & - & & \\
$\quad$ I & 3 & 4 & 5 & 0.951 \\
II & 11 & 14 & 17 & \\
$\quad$ III & 2 & 3 & 4 & \\
IV & - & - & - & \\
TNM Stages & 6 & 9 & 9 & \\
$\quad$ I & 5 & 9 & 10 & \\
II & 4 & 3 & 7 & \\
III & & & & \\
IV & & & & \\
\hline
\end{tabular}

ASA: American Society of Anesthesiology; TNM: tumor-node-metastasis.

Table 3. The distribution of patients with respect to postoperative complications according to study groups

\begin{tabular}{lcccc}
\hline & $\begin{array}{c}\text { Group I } \\
(\mathrm{n}=15)\end{array}$ & $\begin{array}{c}\text { Group II } \\
(\mathrm{n}=21)\end{array}$ & $\begin{array}{c}\text { Group III } \\
(\mathrm{n}=26)\end{array}$ & $p$ \\
\hline Wound infection & 4 & 4 & 5 & 0.72 \\
Eventration/evisceration & 3 & 2 & - & 0.12 \\
Anastomotic leak & - & 1 & 1 & 0.09 \\
Anastomotic hemorrhage & - & 1 & 1 & 0.09 \\
Relaparotomy & 3 & 1 & - & 0.21 \\
Pulmonary infection & 1 & 2 & 3 & 0.60 \\
Surgical mortality & 4 & 4 & 3 & 0.65 \\
\hline
\end{tabular}

presented in Table 3 . There were no significant differences between the groups with respect to postoperative complications. Wound infection rates, re-laparotomy rates and morbidity rates related with evisceration were higher in Groups I and II when compared with Group III, but the difference was not significant statistically.

Operative duration, postoperative mortality, length of hospital stay, hospitalization costs, and five-year survival rates are presented in Table 4 . There were no significant differences between the study groups in terms of operative duration, postoperative mortality and five-year survival rates ( $p>0.05)$. Although it was not statistically significant, the five-year survival rate was higher in Group III, and we think that this difference may be related with the stoma-related complications in Groups I and II. However, significant differences were observed regarding the length of hospital stay and hospitalization costs $(p=0.04$ and $p=0.04$, 
Table 4. Operative duration, postoperative mortality, length of hospital stay, hospitalization costs, and five-year survival rates

\begin{tabular}{lcccc}
\hline & $\begin{array}{c}\text { Group I } \\
(\mathrm{n}=15)\end{array}$ & $\begin{array}{c}\text { Group II } \\
(\mathrm{n}=21)\end{array}$ & $\begin{array}{c}\text { Group III } \\
(\mathrm{n}=26)\end{array}$ & $p$ \\
\hline Operative duration (min) & $215(160-350)$ & $235(170-360)$ & $225(150-325)$ & 0.23 \\
Length of hospital stay (days) & 17.2 & 18.6 & 11.3 & 0.04 \\
Postoperative mortality, $\mathrm{n}(\%)$ & $4(26.7)$ & $5(23.8)$ & $6(23.1)$ & 0.966 \\
Hospitalization cost (TL)* & 9.421 & 10.125 & 6.642 & 0.04 \\
5-year survival, n (\%) & $5(20)$ & $8(38.1)$ & $14(53.8)$ & 0.366 \\
\hline
\end{tabular}

*Based on prices set by the Social Security Institution; TL: Turkish lira.

respectively). The length of hospital stay and hospitalization costs were lower in Group III compared with Groups I and II.

\section{DISCUSSION}

Emergent surgical procedures are required due to intestinal obstruction in approximately $20 \%$ of colorectal cancers. ${ }^{[18]}$ Emergent surgery is associated with high morbidity and mortality rates in patients with distended and unprepared bowel. ${ }^{[19]}$ Several surgical procedures have been used and studied in the management of malignant colonic obstructions, but recently, the classical approaches are increasingly being replaced by single-step subtotal or total colectomy involving resection and primary anastomosis with or without colonic irrigation. ${ }^{[20-24]}$ The need for stoma, which is often left open due to lack of opportunity for closure, is eliminated in these single-step procedures, which are also associated with lower mortality and morbidity rates. ${ }^{[10,11,15-17]}$ This study was designed in order to compare the effectiveness of emergent subtotaltotal colectomy and primary anastomosis with other surgical methods in the emergent treatment of malignant obstructive lesions of the left colon.

Colon cancers manifest by colonic obstruction in approximately $30 \%$ of the patients. ${ }^{[3,4]}$ In the present study, the rate of emergent surgery due to obstruction was noted as $19.38 \%$. Moreover, the left colonic malignant obstruction rate was $81.6 \%$ in our study. Targownik et al. ${ }^{[25]}$ reported this rate as ranging from $65-90 \%$ in their series. The reasons why malignant obstructions mostly occur in the left colon, especially in the splenic flexure, include increased fecal stiffness, anatomical features of the region, and narrower diameter of the left colon compared to the right colon. Resection and primary anastomosis is performed with increasing frequency in the management of obstructive lesions of the left colon. It can be performed either directly or together with intraoperative colonic lavage. Thus, complications caused by multiple surgeries can be avoided. It has been shown that intraoperative colonic lavage prolongs operative duration and does not lower the incidence of anastomosis leak. ${ }^{[7]}$ Intralumi- nal fecal loading and the difference between the proximal and distal colon diameters renders difficulty in terms of anastomosis technique in patients treated by resection and primary anastomosis. ${ }^{[26,27]}$ An increased incidence of anastomosis leak, which is the most significant disadvantage, has currently been reported within $1-7 \%$ in several studies, and the mortality rate has been reported to be $2-9 \% .{ }^{[25]}$ In our clinic, we prefer to perform a colostomy in patients with resection and anastomosis in order to lower the morbidity and mortality rates related with anastomosis leakage. In the present study, anastomosis leak was noted in one patient undergoing resection, primary anastomosis and diverting ileostomy and in one patient undergoing subtotal-total colectomy; it closed spontaneously without any need for intervention. Many studies comparing two-step procedures requiring colostomy and resection plus primary anastomosis have demonstrated that length of hospital stay was longer, morbidity was higher, and survival was lower in the two-step procedures. ${ }^{[27]}$

Another treatment alternative in obstructive lesions of the left colon is total-subtotal colectomy plus anastomosis between the ileum and rectum or sigmoid colon. The tumor can be resected in a single session and stoma complications can be avoided. In some studies, it has been shown that this surgical procedure has an advantage in treating synchronous tumors $(11 \%)$ in a single step. ${ }^{[26,27]}$ In this way, the anastomosis between the ileum and rectum/sigmoid colon can be performed with a good technique without contaminating the abdominal cavity. In emergent surgeries, the leakage risk was higher in colo-colonic anastomosis than in ileocolic anastomosis. ${ }^{[27,28]}$ The longer operation time, postoperative diarrhea and incontinence in elderly patients are the disadvantages of the procedure. ${ }^{[7,27]}$ In most of the patients, the diarrhea resolves spontaneously or with medical treatment in a few months. ${ }^{[26,27]}$

Reported complication rates associated with this technique in several series are from $2-8 \%$ for anastomosis leakage, $10-21 \%$ for morbidity, and $0-10 \%$ for 
mortality, which are all lower than with multi-step procedure alternatives. ${ }^{[26,29,30]}$ As a result, as concluded in this study, total/subtotal colectomy can be a good alternative with low morbidity and mortality rates in selected patients when performed by experienced surgeons. ${ }^{[26,28]}$

Another treatment method that is used in malignant colonic obstructions is placement of a self-expandable stent inside the tumor to enable passage. ${ }^{[25,27]}$ As this procedure was not being performed in our center during the period of this study, data regarding this procedure was not available.

Subtotal-total colectomy combined with primary anastomosis was found to be associated with a shorter hospital stay and lower hospitalization costs in the treatment of malignant obstructions of the left colon. Considering the potential existence of a synchronous tumor or polyp, we suggest that subtotal-total colectomy and primary anastomosis performed by experienced surgeons may be a good alternative to other one- or two-step procedures. This technique provides an opportunity for a safer primary anastomosis to be performed without intraabdominal contamination in selected cases.

\section{REFERENCES}

1. McCullough JA, Engledow AH. Treatment options in obstructed left-sided colonic cancer. Clin Oncol (R Coll Radiol) 2010;22:764-70.

2. Aldridge MC, Phillips RK, Hittinger R, Fry JS, Fielding LP. Influence of tumour site on presentation, management and subsequent outcome in large bowel cancer. Br J Surg 1986;73:663-70.

3. Tekkis PP, Kinsman R, Thompson MR, Stamatakis JD; Association of Coloproctology of Great Britain, Ireland. The Association of Coloproctology of Great Britain and Ireland study of large bowel obstruction caused by colorectal cancer. Ann Surg 2004;240:76-81.

4. Ohman U. Prognosis in patients with obstructing colorectal carcinoma. Am J Surg 1982;143:742-7.

5. Baron TH, Kozarek RA. Endoscopic stenting of colonic tumours. Best Pract Res Clin Gastroenterol 2004;18:20929.

6. Alvarez JA, Baldonedo RF, Bear IG, Truán N, Pire G, Alvarez P. Obstructing colorectal carcinoma: outcome and risk factors for morbidity and mortality. Dig Surg 2005;22:17481.

7. Trompetas V. Emergency management of malignant acute left-sided colonic obstruction. Ann R Coll Surg Engl 2008;90:181-6.

8. Cuffy M, Abir F, Audisio RA, Longo WE. Colorectal cancer presenting as surgical emergencies. Surg Oncol 2004;13:14957.

9. De Salvo GL, Gava C, Pucciarelli S, Lise M. Curative surgery for obstruction from primary left colorectal carcinoma: primary or staged resection? Cochrane Database Syst Rev 2002;(1):CD002101.

10. Halevy A, Levi J, Orda R. Emergency subtotal colectomy. A new trend for treatment of obstructing carcinoma of the left colon. Ann Surg 1989;210:220-3.

11. Arnaud JP, Bergamaschi R. Emergency subtotal/total colectomy with anastomosis for acutely obstructed carcinoma of the left colon. Dis Colon Rectum 1994;37:685-8.

12. Forloni B, Reduzzi R, Paludetti A, Colpani L, Cavallari G, Frosali D. Intraoperative colonic lavage in emergency surgical treatment of left-sided colonic obstruction. Dis Colon Rectum 1998;41:23-7.

13. Day TK, Bates T. Obstructing/perforated carcinoma of the left colon treated by resection and the formation of a double colostomy. Br J Surg 1984;71:558-60.

14. Lamah M, Mathur P, McKeown B, Blake H, Swift RI. The use of rectosigmoid stents in the management of acute large bowel obstruction. J R Coll Surg Edinb 1998;43:318-21.

15. Wilson RG, Gollock JM. Obstructing carcinoma of the left colon managed by subtotal colectomy. J R Coll Surg Edinb 1989;34:25-6.

16. Deutsch AA, Zelikovski A, Sternberg A, Reiss R. Onestage subtotal colectomy with anastomosis for obstructing carcinoma of the left colon. Dis Colon Rectum 1983;26:22730 .

17. Klatt GR, Martin WH, Gillespie JT. Subtotal colectomy with primary anastomosis without diversion in the treatment of obstructing carcinoma of the left colon. Am J Surg 1981;141:577-8.

18. Lee YM, Law WL, Chu KW, Poon RT. Emergency surgery for obstructing colorectal cancers: a comparison between rightsided and left-sided lesions. J Am Coll Surg 2001;192:71925.

19. Runkel NS, Hinz U, Lehnert T, Buhr HJ, Herfarth Ch. Improved outcome after emergency surgery for cancer of the large intestine. Br J Surg 1998;85:1260-5.

20. Chua CL. Surgical considerations in the Hartmann's procedure. Aust N Z J Surg 1996;66:676-9.

21. Dudley HA, Racliffe AG, McGeehan D. Intraoperative irrigation of the colon to permit primary anastomosis. Br J Surg 1980;67:80-1.

22. Turan M, Ok E, Sen M, Koyuncu A, Aydin C, Erdem M, et al. A simplified operative technique for single-staged resection of left-sided colon obstructions: report of a 9-year experience. Surg Today 2002;32:959-64.

23. Arnaud JP, Tuech JJ, Duplessis R, Pessaux P. et al. Role of subtotal/total colectomy in emergency treatment of occlusive cancer of the left colon. [Article in French] Ann Chir 1999;53:1019-22.

24. Torralba JA, Robles R, Parrilla P, Lujan JA, Liron R, Piñero A, et al. Subtotal colectomy vs. intraoperative colonic irrigation in the management of obstructed left colon carcinoma. Dis Colon Rectum 1998;41:18-22.

25. Targownik LE, Spiegel BM, Sack J, Hines OJ, Dulai GS, Gralnek IM, et al. Colonic stent vs. emergency surgery for management of acute left-sided malignant colonic obstruction: a decision analysis. Gastrointest Endosc 2004;60:86574.

26. Hennekinne-Mucci S, Tuech JJ, Bréhant O, Lermite E, Bergamaschi R, Pessaux P, et al. Emergency subtotal/total colectomy in the management of obstructed left colon carcinoma. Int J Colorectal Dis 2006;21:538-41.

27. Tan KK, Sim R. Surgery for obstructed colorectal malignancy in an Asian population: predictors of morbidity and comparison between left- and right-sided cancers. J Gastrointest 
Surg 2010;14:295-302.

28. Balogh A, Wittmann T, Varga L, Zöllei I, Lázár G, Baradnay G, et al. Subtotal colectomy for the treatment of obstructive left colon cancer. Follow-up results. [Article in Hungarian] Orv Hetil 2002;143:1577-83. [Abstract]

29. Arnaud JP, Cervi C, Duplessis R, Cattan F. [The role of sub- total/total colectomy in the urgent treatment of obstructive cancer of the left colon]. [Article in French] J Chir (Paris) 1997;134:267-70. [Abstract]

30. Vuković M, Moljević N. Total colectomy-options in management of acute obstruction of the left-side colon. [Article in Serbian] Med Pregl 2008;61:43-7. [Abstract] 